\title{
O ACESSO À JUSTIÇA E A PROPOSTA HABERMASIANA PARA UM PROCESSO CIVIL DISCURSIVO*
}

\section{ACCESS TO JUSTICE AND THE HABERMASIAN PROPOSAL FOR A DISCURSIVE CIVIL PROCEDURE}

Eder Fernandes Monica**

\begin{abstract}
Resumo: O presente artigo tem por objetivo mostrar como é possível, por meio da teoria procedimental do direito, ter um processo discursivo que, conseqüentemente, melhore o acesso à justiça no tocante ao direito processual civil brasileiro. Com isto, será possível superar a tensão que ocorre entre a necessidade de satisfação da pretensão e legitimidade dessa satisfação, ou seja, o correto provimento jurisdicional. Para tal intento, alguns institutos do direito processual civil brasileiro serão criticados e analisados sob o viés da teoria de habermas.
\end{abstract}

Palavras-chave: Acesso à justiça. Processo civil. Teoria procedimental do direito.

\begin{abstract}
By using the theory of legal procedure, the present article aims to show how it is possible to obtain a discursive process which, consequently, improves access to justice regarding the Brazilian civil procedure law. Thus, it will be possible to overcome the existing tension between the necessity of satisfaction of the claim and the legitimacy of such satisfaction, that is, the correct jurisdictional provision. In order to do that, some elements of the Brazilian civil procedure law will be criticized and analyzed from the perspective of the theory conceived by Habermas.
\end{abstract}

Keywords: Access to justice. Civil procedure. Theory of legal procedure.

Artigo extraído da dissertação apresentada à Universidade Estadual de Londrina, em 25 de fevereiro de 2008, intitulada "A possibilidade de uma única sentença correta para cada caso", para a obtenção do grau de mestre, sob orientação do professor doutor Luiz Fernando Bellinetti.

"Mestre em Direito pela Universidade Estadual de Londrina. Professor do curso de direito da UNDB, em São Luis do Maranhão. 


\section{INTRODUÇÃO}

A tensão entre faticidade e validade, conforme apresentada por Habermas, é imanente ao direito e manifesta-se na jurisdição como tensão entre o princípio da segurança jurídica e a pretensão de tomar decisões corretas. Dentro do direito processual, esta tensão também se manifesta nas tarefas de se chegar à satisfação da pretensão, o que levaria à pacificação do conflito, mas ao mesmo tempo esta pacificação deve ser legítima, ou seja, o julgador precisa decidir de modo correto para o caso. Somente dessa maneira é que o processo poderá propiciar às partes o "acesso à justiça”, pois, conforme expõe a doutrina jurídica brasileira, acesso à justiça não significa uma mera "admissão ao processo, ou possibilidade de ingresso em juízo" (CINTRA, 2002, p. 33). Conforme Cintra, Grinover e Dinamarco, um efetivo acesso à "justiça” se dá quando o sistema jurídico propicia condições para que o maior número possível de pessoas demandem e se defendam adequadamente. Isso inclui a superação de dificuldades econômicas "que impeçam ou desanimem as pessoas de litigar ou dificultem o oferecimento de defesa adequada" (CINTRA, 2002, p. 34), como o oferecimento de justiça integral e gratuita; e inclui também a eliminação do impedimento de litigar para defesas de interesses transindividuais, como no caso da "Lei da Ação Civil Pública" (Lei 7.347/85), que elenca os casos em que algumas entidades podem pleitear judicialmente em prol de interesses coletivos ou difusos. O nexo interno entre autonomia pública e autonomia privada e como ele se processa no interior do sistema de direitos é o modo como Habermas fundamenta o direito de acesso à "justiça”, o qual somente será efetivo se as condições necessárias para o ingresso ao sistema jurídico forem estendidas ao maior número possível de pessoas. Os cidadãos só poderão usufruir dos instrumentos processuais se puderem contar com direitos políticos que garantam este desfrute. $\mathrm{E}$ as condições de relativa simetria entre os cidadãos serão adquiridas somente se forem garantidas as condições materiais para desenvolver sua autonomia privada.

No direito processual brasileiro, autores como Dinamarco, Grinover e Cintra entendem que a pacificação é o escopo magno da jurisdição e, por conseqüência, de todo o sistema processual. Entendem que hoje prevalecem as idéias do estado social, que almeja realizar plenamente os valores humanos, dentro de um objetivo-síntese que é alcançar o "bem comum”, sendo que a projeção particularizada deste bem comum na jurisdição é a "pacificação com justiça" (CINTRA, 2002, p . 4-5). Cabe ressaltar que os conceitos de valores humanos e de bem comum possuem uma outra conotação na teoria de Habermas, bem como o entendimento acerca da prevalência do estado social na sociedade 
atual. Em exposição que se verá adiante, esta doutrina tem raiz nos estudos de Chiovenda a respeito da função do processo como atuador do direito material.

$\mathrm{Na}$ doutrina processual, Aroldo Plínio Gonçalves (1992, p. 175-7) ponderou que esta concepção do escopo do processo ser a pacificação com justiça é imprecisa, pois a finalidade do processo não pode ser confundida com a finalidade da medida jurisdicional imposta pelo provimento. $\mathrm{O}$ direito material a ser atuado é somente aquele constatado pelo correto procedimento e por meio do contraditório, caso contrário não há como atuar um direito inexistente, visto que este só virá a ser no caso concreto, no momento da aplicação de uma norma. O jurista também acrescenta que, ao afirmar que a finalidade do processo é pacificar com justiça, suscita-se uma questão imediata: "os direitos garantidos no processo não se confundem com o direito material que será objeto de exame na sentença”. Não se pode estabelecer como finalidade do processo a valoração da justiça do direito material, pois "a atuação do direito poderá ser valorada como justa, se justo for o direito a ser atuado”.

Para que os cidadãos tenham acesso a uma ordem jurídica justa, que ao mesmo tempo garanta a segurança jurídica e decisões corretas, a ordem jurídica deve possuir princípios e garantias que permitam um integral acesso à justiça, sendo que dentro do âmbito especificamente processual, devem ser oferecidos, além da mais ampla admissão de pessoas e causas ao processo, a garantia de observância das regras do devido processo legal, bem como a garantia da participação plena das partes na formação do convencimento do juiz que julgará a causa. Para ir mais além, o direito deve proporcionar e garantir condições para uma participação ativa nos procedimentos de produção de normas nos mais diversos níveis.

Diante disto, é necessário uma revisitação dos institutos processuais para que se consiga uma técnica processual mais adequada, capaz de atender aos anseios de uma sociedade pós-convencional e pluralista. A teoria discursiva possui manancial para abastecer novos caminhos e visões que possam responder a estes anseios. Com a pergunta acerca da possibilidade de uma única sentença correta para cada caso, podemos visualizar no campo específico da filosofia do direito as diversas correntes que se desenvolveram ao longo do tempo e que tentaram solucionar a questão da fundamentação e aplicação das normas.

A proposta de Habermas com a sua teoria foi apresentar uma possibilidade de superação da dicotomia entre segurança jurídica e decisão justa e que não recorresse a fundamentos últimos. Com uma compreensão procedimentalista do direito, e sabendo-se possível chegar a uma única sentença correta para os casos, pelo menos in the long run, ou seja, enquanto for mantido o acordo 
referente à decisão, o juiz da teoria discursiva tem que conceber sua interpretação construtiva do direito, como a apresentada por Dworkin, como um empreendimento comum, sustentada pela comunicação pública dos cidadãos, o que levaria a um maior acesso à justiça e uma maior legitimidade das decisões, sem que se perca em termos de segurança. Em vez de um juiz com privilégios cognitivos, buscar-se-ia um processo que fosse aberto ao entendimento de todos. Não seria suficiente uma autolegitimação fática dos juízes apenas, como propuseram muitas teorias que se desenvolvem fundadas na esperança de uma melhor formação dos juízes. Isso recairia numa prática de especialistas do direito, que não proporcionaria uma intensa abertura democrática.

Um processo discursivo não visaria a um "fim natural”, à busca de um suposto direito natural passível de ser intuído pelos homens. O que há é um acordo não coercitivo, uma ordem de argumentos por enquanto coerentes, constituído de modo provisório, numa legítima busca cooperativa da verdade. Os direitos processuais devem ser aptos a garantir a cada sujeito a pretensão a um processo eqüitativo. As questões levadas ao processo são expostas a uma "clarificação" discursiva, permitindo aos atingidos adquirirem a segurança de que no processo só serão decisivos para a sentença judicial os argumentos que forem relevantes e não arbitrários. É por isto que Habermas afirma que as qualidades constitutivas da validade de um juízo devem ser procuradas não apenas na dimensão lógico-semântica da construção de argumentos e da ligação lógica entre proposições, mas também na dimensão pragmática do próprio processo de fundamentação. A correção de juízos normativos não pode ser explicada no sentido de uma teoria da verdade como correspondência, pois direitos são uma construção social, a qual não pode ser hipostasiada em fatos.

Ao concluir o capítulo referente à indeterminação do direito e a racionalidade da aplicação judicial (HABERMAS, 2005, cap. 5), Habermas dá alguns apontamentos genéricos de como poderia se desenvolver uma teoria discursiva no direito. Recorrendo ao direito processual civil e penal alemão, a partir de um levantamento feito por Günther, Habermas mostra como sua teoria pode se estruturar com a instauração jurídico-processual dos discursos jurídicos. Num primeiro momento, ele analisa os aspectos da realização de uma atividade "legitimamente argumentativa" (DUTRA, 2006a, p. 29), sob a perspectiva do olhar imparcial do juiz. Já num outro momento, ele analisa os aspectos institucionais para a garantia de um ordenamento aberto a uma legitimação democrática. Com base nestes apontamentos, algumas questões específicas do direito processual brasileiro serão analisadas sob o viés da teoria discursiva. 
$\mathrm{O}$ acesso à justiça e a proposta Habermasiana para um processo civil discursivo

\section{A INSTAURAÇÃO DE DISCURSOS JURÍDICOS NO DIREITO PROCESSUAL CIVIL BRASILEIRO}

O debate sobre a da função do processo tem por pano de fundo as discussões da dogmática do direito civil alemão, na disputa entre direitos objetivos e direitos subjetivos. $\mathrm{Na}$ origem da discussão podem-se verificar duas escolas diferentes acerca do ordenamento jurídico. De um lado estão aqueles que acreditam ser a função do ordenamento a de fazer atuar as normas abstratas, declarando o direito que preexiste no ordenamento. É a chamada teoria dualista do ordenamento jurídico. Para Chiovenda, o ordenamento jurídico estaria cindido entre direito material, que ditaria as regras abstratas que se tornariam concretas no momento em que o fato enquadrado nas suas previsões ocorresse, sem qualquer participação do juiz, e direito processual (CINTRA, 2002). Assim, o julgador somente declararia o direito aplicável ao caso concreto, ou, conforme expõe Chiovenda, a jurisdição seria a atuação da vontade concreta da lei por meio da substituição da atividade alheia pela dos órgãos públicos, ou afirmando a existência da vontade da lei, ou tornando-a efetiva na prática. Por esta idéia, a norma concreta nasceria antes e independentemente do processo (CINTRA, 2002). Esta concepção procura se adaptar a essa noção declaratória de jurisdição, tendo a função de "atuar" o direito (BELLINETTI, 1994, p. 71). Ela é resultante da "concepção pura de positivismo" (BELLINETTI, 1994, p. 61-2), a que resume o direito ao sistema legal e aos princípios a ele inerentes. Neste caso, a sentença seria um ato de mera inteligência do juiz (BELLINETTI, 1994).

Do outro lado está a concepção unitária do ordenamento jurídico, na qual o juiz faria mais do que simplesmente declarar o direito, pois teria também uma função constitutiva. $O$ direito objetivo não disciplinaria sempre todos os conflitos de interesses. Por isto, o processo seria necessário para a complementação dos comandos da lei. A cisão entre direito material e direito processual, aqui, não seria tão nítida: "o processo participa da criação de direitos subjetivos e obrigações, os quais só nascem efetivamente quando existe uma sentença" (CINTRA, 2002, p. 39). Neste sentido é que Carnelutti entendeu por lide, num primeiro momento de seus estudos, qualquer conflito de interesses que for regulado pelo direito e que busca uma composição justa feita nos termos do direito. O escopo do processo seria a "justa composição da lide", estabelecendo qual norma de direito material disciplina o caso, dando razão a uma das partes (CINTRA, 2002, p. 133). Suas raízes estão nas doutrinas positivistas críticas do positivismo puro, tendo Kelsen como o principal expoente (BELLINETTI, 1994). 
Por trás dessa discussão também está aquela a respeito da evolução do conceito de direito de ação. Pela teoria imanentista, que remonta à Savigny, a ação seria o direito de pedir em juízo o que nos é devido. A ação e o processo seriam meros capítulos do direito substancial, sendo aquela vinculada ao direito subjetivo material. Com a polêmica entre Windscheid e Müther, foi admitido um direito de agir que poderia ser exercido contra o estado e contra o devedor. A partir disto, as teorias processualistas desenvolveram a idéia de que o direito de ação era autônomo em relação ao direito material, sendo um "direito subjetivo público oponível ao estado” (GONÇALVES, 1992, p. 137). À teoria concreta filiou-se Chiovenda, pela qual formulou a tese da ação como direito potestativo ${ }^{1}$. O direito de ação é um direito autônomo, embora não seja um direito subjetivo. Dirige-se contra o adversário e configura o poder jurídico de dar condições para que a vontade concreta da lei atue. Ele seria, em resumo, um direito que pertence a quem tem razão, contra quem não a tem. Nesse sentido, a ação seria um direito autônomo e concreto. Já seguindo a linha de pensamento daqueles que entendem a ação como direito autônomo, mas abstrato, o direito de ação independeria da existência efetiva do direito material invocado. Haveria ação mesmo quando uma sentença negasse a pretensão do autor, sendo necessário para a caracterização do direito de ação apenas que o autor mencione um interesse seu protegido em abstrato pelo direito (CINTRA, 2002).

É importante verificar que somente com a desvinculação do direito de ação em relação ao direito subjetivo material é que foi possível a atribuição de garantias de defesa e de proteção jurisdicional ante possíveis violações de direitos. Nesse sentido, a teoria discursiva procurou fundamentar um direito de acesso à justiça que assegurasse a todas as pessoas idêntica proteção jurídica, igual direito de ser ouvido, igualdade na aplicação do direito, igual trato perante a lei, etc. Com a conjugação do direito a iguais liberdades subjetivas de ação, do direito de pertencimento a uma comunidade jurídica e do direito de ação é que se estabelece, para Habermas, o código do direito, que deve ser neutro e livre de qualquer ingerência material (HABERMAS, 2005).

A maioria dos processualistas brasileiros define a natureza jurídica da ação como um direito de natureza pública, que tem por conteúdo o exercício da jurisdição e de natureza constitucional. Para Calmon de Passos (2001), é o processo que deve condicionar o produto, e não o contrário. Como o direito

${ }^{1}$ Com Chiovenda se estabeleceu a concepção de que o direito de ação seria um direito subjetivo de natureza potestativa, e a de que o processo seria uma relação jurídica e um instrumento de atuação da lei (GONÇALVES, 1992, p. 137). 
não é algo dado aos homens pela natureza, mas por eles produzido, foi importante todo esse processo de autonomização do direito de ação (PASSOS, 2001). O processo deixou de ser visto como um mero instrumento do direito material e é por isto que se critica a tese de uma instrumentalidade do processo no sentido de submissão ao direito material, dando ao processo um caráter secundário, de dependência. Segundo Bedaque, o direito processual tem a finalidade de garantir que a norma substancial seja atuada, ou seja, o direito processual atuaria quando o direito material não fosse realizado espontaneamente (BEDAQUE, 2003). Seria um instrumento cuja utilidade é medida em função dos benefícios que ele possa trazer para o titular de um interesse protegido pelo ordenamento jurídico material. Assim, a natureza instrumental do direito processual impõe que os seus institutos sejam concebidos em conformidade com as necessidades do direito substancial (BEDAQUE, 2003).

Dinamarco entende que o sistema processual deve guardar "perene correspondência" com a ordem constitucional, no sentido de acompanhar as "opções políticas do constituinte, as grandes linhas ideológicas abrigadas sob o pálio constitucional”. O processo deve ser o espelho e salvaguarda dos "valores individuais e coletivos que a ordem constitucional vigente entende de cultuar". Para fundar a sua teoria da instrumentalidade do processo, o autor se baseia num conceito de justiça de conteúdo substancial e efetivo e num conceito de estado que busca ser o provedor dos seus cidadãos, que preza pelo bem-estar coletivo por meio de uma prática "declaradamente intervencionista", que age sobre a ordem econômica e social, "buscando sua modelagem segundo os objetivos da ideologia aceita" (DINAMARCO, 2003, p. 33-5). Nesse sentido, o processo teria uma forte vinculação com as nuances políticas de cada período, pois tem uma estrutura teleológica que se manifesta nos escopos do processo (DINAMARCO, 2004, cap. 4). Os fins da jurisdição não seriam apenas jurídicos, mas também sociais - pacificação com justiça e educação - e políticos - a participação, a afirmação da autoridade do estado e de seu ordenamento ${ }^{2}$. O processo, então, ficaria preso ao ethos de uma comunidade e a um conceito substancial de justiça, que são alvos de crítica da teoria discursiva, no que concerne à relação entre direito e poder e direito e

\footnotetext{
${ }^{2}$ Aroldo Plínio Gonçalves desenvolve uma crítica a respeito dos escopos meta-jurídicos do processo no item 9.6 do seu livro "Técnica processual e teoria do processo" (GONÇALVES, 1992, p. 179-88).
} 
moral, e por não atentar à divisão habermasiana entre discursos morais, éticos e pragmáticos.

Para Calmon de Passos, se os juristas contemporâneos atentassem para a importância dos estudos a respeito da linguagem, não dariam tanta ênfase à instrumentalidade do processo, ou a ênfase seria diferente. $O$ direito é linguagem, e linguagem é também o direito aplicado ao caso concreto, que assume a forma de uma decisão judicial ou administrativa. Não dá para se dissociar o direito de seu processo de enunciação, pois direito pensado e o processo do seu enunciar são uma só coisa. Se direito é linguagem, o processo nada mais é que a linguagem que dá concreção ao direito. Assim, para ser rigoroso com os termos, Calmon de Passos conclui que "falar de 'instrumentalidade' em dogmática é utilizar-se palavra de todo inadequada”, por se tratar de um reducionismo simplificador ao ser identificada a instrumentalidade com o processo. O processo deve proporcionar a oportunidade para que as pessoas possam se "revelar", pois esta é a estrutura do discurso e da ação, e não se constituir em meio de propagação de uma "verdade pressuposta". Por isso, falar de instrumentalidade no nível da comunicação, do discurso, da ação, "ou é imaturidade de reflexão, por déficit filosófico, ou manipulação ideológica perversa, por déficit de solidariedade". O direito está situado no mundo da ação e do discurso, no qual procuramos dar sentido e significação ao nosso agir. Assim, se formos usar a palavra instrumentalidade no processo teremos que dar a ela significado diferente do que aquele utilizado em nível de interação do homem com a natureza (PASSOS, 2001). A instrumentalidade do processo deve ser entendida como o meio para os destinatários do processo formarem e aplicarem o seu próprio direito e disso não se conclui que "a técnica se desenvolve pela técnica e para a técnica" (GONÇALVES, 1992, p. 168-70).

O que se quer afirmar é que o processo vai muito mais além do que ser um instrumento para a realização das opções políticas do legislador, transformandose num legítimo meio discursivo que não se confunde com a simples realização de uma presumida vontade da lei ou de um "papel-missão do juiz" chamado a "julgar com justiça” (GONÇALVES, 1992, p. 177). As críticas da teoria discursiva ao solipsismo judicial já expressaram isso.

Habermas (2005) afirma que em relação às restrições sociais e temporais do processo pode-se dizer que no aspecto temporal, mesmo não havendo uma estipulação com relação à duração máxima dos processos, os prazos impedem que as questões em litígio sejam tratadas dilatoriamente e fiquem à mercê das vontades das partes em dar andamento ao processo. Pelo aspecto social, a 
$\mathrm{O}$ acesso à justiça e a proposta Habermasiana para um processo civil discursivo

distribuição dos papéis sociais no processo estabelece uma simetria entre os pólos da ação. Isso seria um pouco mais do que a noção de que as partes apenas "colaboram" (LIEBMAN, 2003, p. 45) com o juiz no processo e que estejam sempre em posições contrapostas (LIEBMAN, 2003), numa luta de ações e reações, de ataques e defesas (CALAMANDREI, 1973). Esta simetria entre os pólos da ação é que proporcionará uma solução "que faça justiça a ambos os participantes do conflito e do processo" (CINTRA, 2002, p. 33). Nesse sentido é que o direito ao contraditório se mostra como a garantia de participação, em simétrica paridade, daqueles aos quais se destinam os efeitos da sentença, ou seja, aos que são chamados de interessados (GONÇALVES, 1992). Mas esta garantia não se confunde com "participação coativa" (GONÇALVES, 1992, p. 159). O contraditório seria uma oportunidade, e não uma obrigatoriedade, o que vai ao encontro das idéias de Habermas a respeito dos espaços de liberdade estratégica dentro do direito.

No que concerne às provas, os ônus vêm distribuídos de forma mais ou menos unívoca entre as partes e encontra-se estruturado de modo "agonístico" (DUTRA, 2006a, p. 29), como se fosse uma espécie de competição entre as partes que perseguem seus próprios interesses. Se é tarefa do juiz decidir o litígio, deve haver critérios que o permita resolver a controvérsia quando os fatos principais não estão provados. Mesmo se tratando de espaços de ação estratégica, esta estrutura está organizada de forma tal que permita a apreensão e tematização de todos os fatos e meios relevantes para a constituição do estado de coisas, estabelecendo-se assim como uma norma de julgamento. Nesse sentido é que Marinoni afirma que o ônus da prova dirige-se, em princípio, ao juiz, e também às partes, pois orienta sua conduta processual em face da prova (MARINONI, 2004).

A idéia de prova está ligada à tentativa de racionalização da descoberta da verdade. O juiz, no processo, tem por função a "reconstrução dos fatos" que a ele são apresentados e a aplicação a estes das regras abstratas do ordenamento jurídico positivo. Entretanto, esta função foi encarada de diferentes formas no decorrer evolutivo da ciência processual. Por muito tempo esteve ligada a uma simples idéia de o juiz ser a "boca da lei”, cabendo-lhe, segundo Marinoni (2004, p. 290), um juízo de "concreção da regra aos fatos", extraindo-se a "conseqüência aplicável ao conflito, disciplinando-o na forma como preconizada pelo legislador”. É certo que a função da prova é de suma importância para o processo. Conforme expõe Chiovenda (2002, p. 18-9), o magistrado só terá condições de determinar qual a regra abstrata que deve ser aplicada ao caso concreto se ele souber como as coisas se passaram, ou seja, 
como os fatos se desenvolveram. A norma fica condicionada à verificação de determinados fatos. Toda a vez que se verifica os fatos ou grupos de fatos previstos pela norma, a norma que antes representava uma vontade geral, abstrata, hipotética, passa a atuar a vontade concreta da lei, pois nasce, na verificação da ocorrência do fato previsto pela lei, uma vontade particular que está propícia a atuar no caso determinado. Marinoni (2004, p. 291, nota 4) aponta que é por causa desta idéia que Chiovenda define jurisdição como aquela que tem por escopo a atuação da vontade concreta da lei. Chiovenda, preso ao espírito de sua época, afirma que a interpretação é obra somente da doutrina e que ao juiz cabe-lhe apenas aplicar a regra. A importância da verdade no processo levou Chiovenda (1998) a dividir o processo de conhecimento entre a demanda e a sentença, processo este que seria composto por uma série de atos que objetivariam dar ao juiz condições de se pronunciar em relação à demanda. Marinoni (2004, p. 292) também aponta que Liebman (2003, p. 4) conceitua o termo "julgar" como a valoração de determinado fato que ocorreu no passado feita com base no direito vigente e determinadora da norma concreta que regerá o caso.

Este entendimento de que a tarefa do juiz é a de aplicar o direito objetivo ao caso concreto faz imprescindível "a reconstrução dos fatos a fim de que a hipótese prevista na norma seja adequadamente aplicada”. A adequabilidade estaria na "maior ou menor aproximação da hipótese descrita na regra com a realidade descoberta”. É por isto que Marinoni afirma que a verdade material (ou substancial) seria, nessa linha histórica, o escopo básico da atividade jurisdicional. Este ideal de "busca incessante da verdade absoluta", ou nas palavras de Carnelutti (1973), a busca da "essência material do fato" (p. 168), legitimaria a função judicial e serviria como "válvula regulatória" de sua atividade, "na medida em que a atuação do magistrado somente será legitimada dentro dos parâmetros fixados pela verdade por ele reconstruída no processo" (MARINONI, 2004, p. 292-4). Apesar de para muitos esta idéia de verdade substancial já estar superada, a maioria dos processualistas modernos ainda têm como pressuposto que a verdade é uma concordância entre um fato da realidade sensível e a idéia que fazemos dele, fruto de uma filosofia vinculada ao paradigma do objeto (MARINONI, 2004). Marinoni conclui que o conceito de verdade no processo é intimamente ligado à idéia de verdade que se tem nos demais ramos do conhecimento (2004, p. 294-5). Assim, Marioni (2004) constata que a prova não é assunto versado exclusivamente pelo direito processual e, por isto, o seu conceito, sua função e suas particularidades devem ser informadas por elementos das mais diversas ciências, ingressando no direito processual com visão e regime particulares. 
A reconstrução dos fatos passados é influenciada por vários aspectos subjetivos, como os das pessoas que assistiram os fatos, ou os do julgador, que receberá e construirá o seu convencimento a partir das narrações ou provas de outra espécie. A respeito desta questão, Marinoni afirma que o perceptor de uma informação sempre altera o seu conteúdo, pois o absorve à sua maneira, acrescentando-lhe caracteres pessoais que acabam distorcendo a realidade. Desse modo, o julgador jamais poderá excluir a possibilidade de que as coisas podem ter acontecido de maneira diversa da que lhe é apresentada. Além disto, outras particularidades acabam contribuindo para a não apreensão da verdade absoluta, porque no processo também se encontram limites legais para a atividade probatória, excluindo alguns meios de provas que podem afetar outros interesses (MARINONI, 2004), ou como afirmava Chiovenda (2002), no interesse da paz social, a lei traça limites à pesquisa da verdade.

Marinoni traz para o direito probatório brasileiro uma aplicação dos estudos da teoria discursiva, procurando avaliar a questão da verdade por meio do procedimento utilizado para se chegar a ela. A partir da premissa de que "não é objetivo concreto do juiz encontrar a verdade (absoluta) no processo", o autor conclui que a função da prova é de ser um meio "retórico" indispensável ao debate judiciário: "o processo deve ser visto como palco de discussões; a tópica é o método da atuação jurisdicional e o objetivo não é a reconstrução do fato, mas o convencimento dos demais sujeitos processuais sobre ele”. A razão vai centrar-se na comunicação e não na reflexão isolada de um só sujeito, sendo que o verdadeiro e o falso não se originarão nas coisas, nem na razão individual, mas no procedimento. A verdade, nesse contexto não absoluto, vai ser, ao menos para os participantes, o resultado do processo, atingido após o discurso, sendo algo provisório, prevalecendo apenas enquanto se verificar o consenso, e para uma situação específica e concreta (MARINONI, 2004).

Com base na teoria discursiva, Marinoni (2004) pode então questionar a vinculação da idéia de prova com o passado, como se fosse possível, por meio da reconstrução dos fatos passados, apresentar ao juiz meios que o convença sobre a efetiva ocorrência de tais fatos. Para o autor, "é impossível o restabelecimento dos fatos pretéritos”. A prova assumirá, deste modo, a função de "fundamento para a escolha racional" da hipótese que irá servir de conteúdo para a decisão judicial, sendo apta a justificar a escolha de uma das teses trazidas pelas partes ao processo. Por isso, Marinoni entende que a prova pode ser definida como um meio retórico que vem regulado pela lei e tem por destino o convencimento do juiz acerca da validade das proposições apresentadas no processo. É importante ressaltar que essa desvinculação da prova com a verdade 
não quer dizer que o juiz não deva pautar-se pela meta de perseguir sempre uma verdade ideal no processo. Entretanto, é necessário estar ciente das limitações que se têm quando se trata do instituto da prova no processo, pois é impossível se chegar ao encontro da "verdade" (MARINONI, 2004, p. 307-8).

Dentro deste contexto, a prova não se destinará a provar fatos, mas as "afirmações de fato" (MARINONI, 2004, p. 308-9). A alegação é que pode estar em consonância com o que se passou, e não o fato, pois este não pode ser qualificado como verdadeiro ou falso, porque ou ele existe ou não existe. Somente as alegações sobre um fato é que serão passíveis de serem qualificadas como verdadeiras ou falsas. Tratando-se de uma teoria que privilegia a argumentação dentro do processo, cabe ressaltar algumas regras que auxiliam no processo argumentativo, como a que exige que ao processo sejam trazidos somente os fatos pertinentes e relevantes para a solução do litígio, pois só estes serão objetos de prova, e a regra que permite que no processo sejam alegados somente os fatos principais, pois os fatos secundários podem ser apreciados pelo juiz ainda que não tenham sido afirmados pela parte interessada.

Marcelo Cattoni de Oliveira (2001), munido também do arsenal teórico proporcionado pela teoria discursiva do direito, critica algumas dicotomias criadas pela doutrina jurídica. Uma delas é a dicotomia que se produziu na doutrina processualista brasileira, com base na lição de autores alemães, entre direito constitucional processual - o conjunto de normas constitucionais que estruturam o direito processual - e direito processual constitucional, ou, simplesmente, processo constitucional - processo por meio do qual a jurisdição constitucional é exercida ${ }^{3}$. Essa distinção surgiu, segundo Oliveira (2001), no contexto histórico de criação de uma jurisdição constitucional concentrada do direito tradicional continental europeu. Seguindo a teoria kelseniana, o legislativo e a corte constitucional estão autorizados a interpretar a constituição; os cidadãos e o juiz comum não. Estes devem presumir a constitucionalidade dos atos normativos e das leis, segundo o entendimento da corte constitucional. Parafraseando Peter Häberle (1997), neste caso poderíamos falar de uma sociedade fechada dos intérpretes da constituição, sociedade esta que, para Oliveira (2001, p. 185),

${ }^{3}$ Segundo Cattoni (2001), a distinção poderia ser resumida da seguinte forma: o direito constitucional processual seria formado a partir dos princípios basilares do devido processo e do acesso à justiça, e se desenvolveria por meio de princípios constitucionais referentes às partes, ao juiz, ao ministério público, enfim, os princípios do contraditó- 
$\mathrm{O}$ acesso à justiça e a proposta Habermasiana para um processo civil discursivo

criou a doutrina das normas constitucionais programáticas, dos direitos fundamentais em sentido objetivo, que equiparou os direitos a bens negociáveis, que inspirou a doutrina dos escopos metajurídicos do processo, que criou a jurisprudência dos valores.

As razões que Oliveira (2001, p. 184) levanta para ir contra essa divisão são duas:

Por um lado, se o direito constitucional é o fundamento de validade de todo o ordenamento jurídico, posto que estabelece os processos através dos quais todas as demais normas são produzidas, quer da perspectiva legislativa, quer da perspectiva da aplicação jurisdicional, não há direito processual que não deva ser, nesse sentido, constitucional. Por outro lado, no Brasil, apesar de vozes discordantes, o controle jurisdicional de constitucionalidade das leis e dos atos normativos é fundamentalmente difuso e incidental, como exigência constitucional basilar no esteio da melhor tradição democrática e constitucional brasileira.

Cattoni leciona que tanto no Brasil, quanto nos Estados Unidos, todo cidadão pode ser considerado como intérprete da constituição: "qualquer cidadão tem o direito de desobedecer a comandos estatais inconstitucionais e qualquer juiz deve pronunciar-se sobre a inconstitucionalidade desses comandos”. Esse direito a desobedecer presume-se do fato de que a decisão judicial acerca da inconstitucionalidade é declaratória e com efeitos retroativos, resultado de um "reconhecimento institucional de um direito concreto a desobedecer” (OLIVEIRA, 2001, p. 185). Com base na afirmação de José Luiz Quadros de Magalhães de que no Brasil toda jurisdição é jurisdição

rio, da ampla defesa, da proibição das provas ilícitas, da publicidade, da fundamentação das decisões, do duplo grau, da efetividade, do juiz natural, etc. Já o direito processual constitucional seria formado a partir de normas processuais de organização da justiça constitucional e de instrumentos processuais previstos nas constituições, afetos à garantia da constituição e à garantia dos direitos fundamentais, controle de constitucionalidade, solução de conflitos entre os órgãos de cúpula do estado, resolução de conflitos federativos e regionais, julgamentos de agentes políticos, recurso constitucional, habeas corpus, amparo, mandado de segurança, habeas data, etc. (OLIVEIRA, 2001, p. 183). No direito processual brasileiro há alguns autores que tratam especificamente dessa divisão. Manuel Galdino da Paixão Júnior (2002), no capítulo IV do seu livro "Teoria geral do processo" trata do direito processual constitucional; José Cretella Neto (2002) apresenta, no capítulo IV de seu "Fundamentos principiológicos do processo civil", quais são os princípios constitucionais do processo civil; Nelson Nery Júnior (1999) é outro processualista que tem uma obra específica sobre o tema, intitulada "Princípios do processo civil na Constituição Federal. 
constitucional, Cattoni aponta que segundo o ordenamento jurídico brasileiro, o controle de constitucionalidade pode ser dado como preliminar de mérito em qualquer processo, podendo o cidadão se opor ou argüir uma inconstitucionalidade, sendo que todo juiz ou tribunal, em qualquer instância, pode e deve apreciar a constitucionalidade de lei ou ato normativo de qualquer espécie.

A ação direta de inconstitucionalidade, o mandado de segurança, o habeas corpus, o mandado de injunção, nada mais são do que meios processuais especiais, complementares e, como tais, devem ser compreendidos como formas de concretização do mais amplo modelo do direito à tutela jurisdicional. A atividade jurisdicional que se desenvolve através deles não cria um estado de exceção e nem mesmo o Supremo Tribunal Federal deve assumir o papel de uma corte constitucional kelseniana ou de presidente do Reich schmitiano. A cidadania não precisa de tutores (OLIVEIRA, 2001, p. 184).

Nesse sentido, mesmo que se admita a existência de um processo constitucional enquanto disciplina de estudo, qualquer processo é constitucional e por isso não se deve levar tão a sério a distinção apresentada, a ponto de se distinguir intimamente o que se relaciona ao processo e o que se relaciona à constituição.

Com o mesmo arsenal teórico, Oliveira (2001) ainda discute alguns entendimentos da doutrina processualista brasileira acerca dos direitos transindividuais. Assim, a distinção que poderia haver entre direitos individuais, coletivos, sociais e difusos é apenas de natureza lógico-argumentativa, pois é só no momento da aplicação das normas que se verificará com precisão qual tipo de direito se trata, inclusive sendo possível a utilização dos mais variados meios processuais, individuais ou coletivos, para a tutela desses direitos. Para Oliveira (2001), tal perspectiva seria mais ampla do que a teoria da interdependência dos direitos, a qual reconhece a interdependência entre os direitos humanos, não os considerando apenas pelo enfoque históricocronológico, marcado pela classificação dos direitos em gerações, mas buscando compatibilizar os direitos uns em relação aos outros. Isto porque neste caso "não se trata simplesmente de uma aplicação ponderada, proporcional ou compromissória de normas constitucionais, semanticamente consideradas, que pretende restringir ou otimizar o exercício dos direitos”. Tal tipo de aplicação de normas é guiada por uma compreensão axiológica dos direitos, compreensão rejeitada por Habermas, por confundir e reduzir "a aplicabilidade ou adequabilidade de uma norma à justificação ou extensão da sua validade ou vigência jurídicas”. Nenhuma predeterminação material pode dar prioridade 
a determinados pontos de vista normativos, em detrimento de outros, porque a adequabilidade de um discurso de aplicação só é procedimentalmente justificada em cada caso concreto (OLIVEIRA, 2001).

Se partirmos de uma compreensão procedimentalista do direito, em que qualquer proposição jurídica é fruto de interpretação, sobre o pano de fundo de visões paradigmáticas concorrentes, não se pode predefinir o conteúdo ou a extensão total de um dispositivo normativo, que ganha sentido a cada novo caso concreto, predeterminando-se materialmente a argumentação. É necessário, mais uma vez, romper com uma teoria material do direito e dos direitos que estabelece um modelo padrão, fixo, para a sua efetivação, até mesmo porque a dinâmica de uma sociedade democrática e pluralista não coaduna com visões privilegiadas e excessivamente concretas do que seja vida, liberdade, igualdade, segurança, trabalho ou até mesmo dignidade humana (OLIVEIRA, 2001, p. 190).

O sistema processual brasileiro é vantajoso nesse sentido, pois o meio coletivo não exclui o individual e vice-versa, havendo entre eles uma "interrelação" explicitada na Lei $8.078 / 90$, sendo que os direitos individuais homogêneos, coletivos, e difusos não estão estabelecidos num catálogo fechado. Com base no Art. 81 do Código de Defesa do Consumidor, só poderemos determinar o tipo de direito transindividual por meio de uma argumentação jurídica de aplicação com vistas ao caso concreto. Se assim não for, as possibilidades de acesso à jurisdição serão reduzidas e se nos prendermos a um catálogo fechado dos direitos transindividuais negaremos de antemão a tutela jurisdicional, pois somente no caso concreto se saberá a respeito da correta categorização de tais direitos (OLIVEIRA, 2001).

Se o direito processual for estruturado deste modo, ou seja, instaurando jurídico-processualmente os discursos jurídicos, demarca-se institucionalmente um espaço interno para o livre processamento de razões nos discursos de aplicação. Os procedimentos que se dão antes da audiência oral - ou do saneamento do processo - servem para definir o objeto de disputa, delimitandose claramente os casos (HABERMAS, 2005). Seguindo a exemplificação de Dutra (2006a), no caso do sistema processual brasileiro podem-se sugerir os seguintes dispositivos: o Art. 5a , LIV da Constituição Federal, que dispõe sobre o devido processo legal; o mesmo artigo em seu inciso LV estabelece como direito individual o contraditório e a ampla defesa.

A relação circular que há no processo entre normas jurídicas e estado de coisas, ou seja, entre variantes de interpretação e relações com fatos, é atenuada pela divisão entre questões de fato e questões de direito, fazendo com que as normas permaneçam "atrás dos bastidores" até que os fatos sejam estabelecidos 
por meio das diligências probatórias encenadas na interação entre as partes do processo. O direito processual compreende o discurso jurídico acerca dos fatos provados ou tidos por verdadeiros quando o tribunal tem que expor e fundamentar seu juízo perante os implicados no processo e ante a opinião pública, fundamentação esta que compreende os fatos que se julga e os motivos da decisão. Os juízes são livres para formar o seu convencimento, pois os procedimentos não normatizam as razões que devem ser consideradas admissíveis, nem tampouco o percurso que a argumentação deve seguir (HABERMAS, 2005).

No caso brasileiro, o Art. 93, III, da Constituição Federal estatui que todas as decisões judiciais devem ser fundamentadas, sob pena de nulidade. O Art. 157 do Código de Processo Penal dispõe sobre a formação da livre convicção do juiz na apreciação da prova e o Artigo 381, III, preceitua que a sentença deverá indicar os motivos de fato e de direito em que se funda a decisão. Já o Código de Processo Civil, em seu Art. 131, preceitua sobre a livre apreciação da prova pelo juiz, que deve se ater aos fatos e circunstâncias constantes nos autos, indicando na sentença os motivos para a formação do seu convencimento. Sobre os prazos, o Art. 192 traz que os prazos peremptórios não podem ser reduzidos ou prorrogados pelas partes. Sobre o objeto, o Art. 286 estabelece que ele deve ser certo ou determinado, delimitando os casos em que ele pode ser genérico.

E por fim, o resultado do processo pode ser reexaminado pelas sucessivas instâncias superiores. Para Habermas, esta possibilidade de revisão institucionalizada serve para duas coisas: à proteção individual do direito sob o duplo ponto de vista da justiça no caso singular; e à uniformização na aplicação do direito e seu aperfeiçoamento, por meio da concentração da jurisdição em tribunais cada vez mais altos até chegar ao tribunal supremo. As partes têm o direito de obter decisões corretas e justas mediante a revisão das sentenças. Essa simples possibilidade de revisão já é um fator que força os tribunais a fundamentarem cuidadosamente a sua decisão. Para que o sistema jurídico seja eficiente e substitua a autotutela ${ }^{4}$, as partes devem estar seguras

\footnotetext{
${ }^{4} \mathrm{~A}$ autotutela seria aquela vigente numa comunidade, na qual ou não haveria direito, ou o direito não estaria acima da vontade dos particulares. Não havendo o direito, inexistiria um órgão estatal com soberania e autoridade para cumprir o direito, nem ao menos existiriam leis. Assim, aquele que pretendesse algo, deveria buscá-lo "com sua própria força e, na medida dela, tratar de conseguir, por si mesmo, a satisfação de sua pretensão" (CINTRA et al., 2002, p. 21).
} 
de que obterão uma decisão correta. Em síntese, "o tribunal tem que decidir cada caso particular mantendo a coerência da ordem jurídica em conjunto" (HABERMAS, 2005, p. 39). No sistema brasileiro, cabe ao Supremo Tribunal de Justiça esta tarefa. O recurso especial é possibilitado quando a decisão à qual se recorre dá à lei federal uma interpretação que seja divergente da que lhe haja atribuído outro tribunal, conforme o Art. 105, III, c, da Constituição Federal. Ao supremo Tribunal Federal cabe função análoga, quando a Constituição Federal, em seu Art. 102, II, a, atribui-lhe a função de uniformização da jurisprudência em face da Constituição Federal, por meio de recurso extraordinário.

\section{CONCLUSÃO}

O intuito deste artigo foi apresentar a crítica de Habermas à teoria do direito contemporânea, mostrando como se daria sua aplicação ao direito processual civil brasileiro por meio da institucionalização de discursos jurídicos. Assim, dentro do âmbito processual, se partirmos de uma perspectiva discursiva, é necessária a reforma do direito processual para torná-lo efetivamente discursivo. Por isso, no trabalho foram levantadas algumas hipóteses de como deveriam ser interpretados alguns institutos do direito processual.

$\mathrm{Na}$ sociedade atual existe uma pluralidade de modos de vida que são concorrentes entre si. Não é mais defensável uma teoria que imponha verdades absolutas como fundamento para o direito, ou seja, que pressuponha fundamentos metafísicos ou de ordem naturalística ou de ordem teológica para as normas de ação. É por isso que o direito deve buscar os princípios de sua justificação dentro do interior da própria realidade jurídica. A teoria procedimental de Habermas propõe um novo caminho para a compreensão do estado democrático de direito, indicando dentro do campo da teoria do direito condições pragmáticas de comunicação para que os discursos jurídicos de justificação e aplicação se realizem. Um direito processual que queira ser um meio comunicativo de realização da liberdade do homem, no qual todos possam se expressar e se encontrar, não pode se comprometer com verdades impostas por uma comunidade de sábios do direito. Somente a partir de uma prática intersubjetiva de produção do direito se poderá garantir a legitimidade das decisões. 


\section{REFERÊNCIAS}

BEDAQUE, José Roberto dos Santos. Direito e processo: influência do direito material sobre o processo. 3. ed. rev. amp. São Paulo: Malheiros, 2003.

BELLINETTI, Luiz Fernando. Sentença civil: perspectivas conceituais no ordenamento jurídico brasileiro. São Paulo: RT, 1994.

CALAMANDREI, Piero. Instituciones de derecho procesal civil. [Trad.] Santiago Sentis Melendo. Buenos Aires: Ediciones Juridicas Europa-America, 1973. v. 1.

CARNELUTTI, Francesco. Institucionas del proceso civil. [Trad.] Santiago Sentis Melendo. 2. ed. Buenos Aires: Ediciones Juridicas Europa-América, 1973. v. 1.

CHIOVENDA, Giuseppe. Instituições de direito processual civil. [Trad.] Paolo Capitanio. I. 3. ed. Campinas : Bookseller, 2002. v. 1.

CINTRA, Antônio Carlos de; GRINOVER, Ada Pellegrini; DINAMARCO, Cândido Rangel. Teoria Geral do Processo. 18. ed. São Paulo: Malheiros Editores, 2002.

CRETELLA NETO, José. Fundamentos principiológicos do processo civil. Rio de Janeiro: Forense, 2002.

DINAMARCO, Cândido Rangel. A intrumentalidade do processo. 11. ed. São Paulo: Malheiros, 2003.

. Instituições de direito processual civil. 4. ed. rev. atual. São Paulo: Malheiros, 2004a. v. 1.

DUTRA, Delamar José Volpato. Da problemática na aplicação do direito: a recepção habermasiana da teoria do direito de Dworkin. Dissertatio, Pelotas, n. 21, p. 61-88, 2005.

A teoria discursiva da aplicação do direito: o modelo de Habermas. Veritas, Porto Alegre, v. 51, p. 18-41, mar. 2006a.

- Justiça como integridade: Dworkin e o princípio da coerência na aplicação do Direito. Phronesis (PUCCAMP), Campinas, v. 8, p. 11-32, 2006b. GALUPPO, Marcelo Campos. Igualdade e diferença: Estado democrático de direito a partir do pensamento de Habermas. Belo Horizonte: Mandamentos, 2002 . 
$\mathrm{O}$ acesso à justiça e a proposta Habermasiana para um processo civil discursivo

GONÇALVES, Aroldo Plínio. Técnica processual e teoria do processo. Rio de Janeiro: Aide, 1992. p. 219.

HABERMAS, Jürgen. Direito e democracia: entre facticidade e validade. 2. ed. Trad. Flávio Bueno Siebeneichler. Rio de Janeiro: Tempo Brasileiro, 2003. v. 1. - Facticidad y validez: sobre el derecho y el Estado democrático de derecho en términos de teoría del discurso. [Trad.] Manuel Jiménez Redondo. 4. ed. Madrid: Trotta, 2005.

LIEBMAN, Enrico Tullio. Manual de direito processual civil. Tocantins: Intelectos, 2003. v. 1.

MARINONI, Luiz Guilherme; ARENDHART, Sérgio Cruz. Manual do processo de conhecimento. 3. ed. rev. atual. amp. São Paulo: RT, 2004.

NERY JÚNIOR, Nelson. Princípios do processo civil na Constituição Federal. São Paulo: RT, 1999.

OLIVEIRA, Marcelo Andrade Cattoni de. Uma justificação democrática da jurisdição constitucional brasileira e a inconstitucionalidade da Lei $\mathrm{n}^{\mathrm{a}}$ 9.686/ 99. Revista da Faculdade de Direito da UFPR, Curitiba, v. 33, n. 36, p. 177207, 2001.

PAIXÃO JR., Manuel Galdino da. Teoria geral do processo. Belo Horizonte: Del Rey, 2002.

PASSOS, J. J. Calmon de. Instrumentalidade do processo e devido processo legal. Revista de Processo, São Paulo, v. 26, n. 102, p. 55-67, abr./jun. 2001. 